\title{
Prevalence and Associated Factors of Alcohol Consumption Among College Students in Gondar Town, Northwest Ethiopia
}

\author{
Shewaye Yismaw ${ }^{1}$, , Hassen Kebede ${ }^{2}$ \\ ${ }^{1}$ Department of Chemistry, College of Natural and computational Science, University of Gondar, Gondar, Ethiopia \\ ${ }^{2}$ Department of Clinical Medicine, Faculty of Veterinary Medicine, University of Gondar, Gondar, Ethiopia
}

Email address:

shewayeyismaw@yahoo.com (S. Yismaw), hassenkebede2010@yahoo.com (H. Kebede)

To cite this article:

Shewaye Yismaw, Hassen Kebede. Prevalence and Associated Factors of Alcohol Consumption Among College Students in Gondar Town, Northwest Ethiopia. Science Journal of Public Health. Vol. 3, No. 4, 2015, pp. 453-459. doi: 10.11648/j.sjph.20150304.12

\begin{abstract}
Background: Excessive alcohol drinking is an important risk factor for many socioeconomic and health problems. The use of alcohol during the teenage and young adulthood years is a common phenomenon in many societies. Thus the study was conducted with the objective of assessing the prevalence and associated factors of alcohol consumption among college students. Methods: A cross-sectional study was conducted from January to May, 2014 among college students in Gondar town. In this study, 454 questionnaires were distributed to Gondar College of teacher's education and Gotoneal college of health sciences students and questionnaires were recollected to assess prevalence of alcohol consumption and associated factors. Result: A total of 454 students participated in the study and all the study participants gave response to the questions. From the survey, it was found that $48.23 \%$ and $26.4 \%$ of the respondents have the experience of alcohol use as ever based and during last thirty days of interview period, respectively. Alcohol consumption experience under differing categories were assessed and a statistically significant difference in alcohol consumption existed only between males $(67.6 \%, 34.1 \%)$ and females $(35.3 \%$, $21.32 \%)$; Muslims (12.8\%, $10.3 \%$ ) and Christians (51.6\%, $27.9 \%)$ with both having P-values less than 0.05 at ever use and last 30 day basis. Based on current findings alcohol drinking was not risk factor for cigarette smoking $(O R=2.93 ; \mathrm{P}>0.1)$ and Khat chewing $(\mathrm{OR}=1.18 ; \mathrm{P}>0.1)$. However, presence of friends with drinking experience was significantly associated for alcohol consumption $(\mathrm{OR}=13.12 ; \mathrm{P}<0.001)$. Conclusion: The proportion of students who have engaged in abusive alcohol use was significantly high. Therefore, we recommend regulatory monitoring on alcohol use and intervention activities to bring behavioral change among college students.
\end{abstract}

Keywords: Alcohol Use, Risk Factors, College Students

\section{Introduction}

There is global concern about drinking trends among young people [1]. Alcohol consumption is an important risk factor for morbidity, mortality and social harm worldwide [24] leading to 2.5 million deaths each year [5]. It is responsible for approximately $4 \%$ of the global burden of disease. This burden is higher in high income countries and among men, accounting for $11 \%$ of all male deaths in the World Health Organization (WHO) of European region in 2004 [3]. Even though the problem is said to be increasing in the developing world, there are no sufficient data on alcohol use and its consequences in many developing countries $[5,6]$.

The use of alcohol during the teenage and young adulthood years is a common phenomenon in many societies.
Epidemiological studies indicate for substantial proportion of alcohol users progressing to problematic drinking or become alcohol dependent. Alcohol consumption at a young age increases the risk of developing alcohol related problems later in life [7-12]. Among youth, drinking often coexists with other problematic behaviors such as poor academic performance and absenteeism which may impair healthy development and successful transition from adolescence to adulthood [13,14].

A study conducted among high school adolescents in Ethiopia from 2001 to 2002 reported that about $8.9 \%$ drunk alcohol at least on a weekly bases [15], where as other reports among students in southern Ethiopia and a private school in Addis Ababa found a prevalence of $57.7 \%$ and $19.2 \%$ respectively [6]. In other sub-Saharan African 
countries like Kenya ever drinking prevalence of up to $15 \%$ were found among secondary school students [16], where some private universities had rates as high as $84 \%$ [17]. A study from South Africa also reported an alcohol use prevalence of $39.1 \%$ among high school adolescents [18].

As in any other developing countries, the distribution and consumption of substances including alcohol are not sufficiently studied in Ethiopia. Alcohol consumption unless complained is not legally prohibited in Ethiopia and there are no age limits practiced on the ground pertaining to alcohol drinking. Culturally, it is consumed in social gatherings and among friends as a leisure time activity and relaxation experience [6]. Description of the interaction between alcohol consumption and other important variables would have an important value to mitigate alcohol related physiological and social health hazards via regulating on alcohol consumption patterns. College students, as very important age of transition with regard to partial freedom from parent care and pre-occupation age before livelihood stabilization, are prone to related substance use and abusive drinking. It also encompasses the stage at greater risk for HIV/AIDS. Although there are published reports in some other localities of Ethiopia, alcohol use and related variables in Gondar town college students were not encountered. In this regard going through alcohol use and related variables among college students in Gondar town seem to be necessary. Therefore; the main objective of this study was to assess the prospects of alcohol consumption among college adolescents in Gondar town.

\section{Materials and Methods}

\subsection{Study Area}

The study was conducted in colleges found in Gondar town, North Gondar administrative zone, Amhara National Regional State, Ethiopia. It is located in Northwest part of Ethiopia, at about $735 \mathrm{~km}$ away from Addis Ababa. Gondar town consist of three public tertiary education institutions namely: Gondar University, Gondar College of teacher's education and Gondar vocational college and private institutions such as Gotoneal, Abyssinia, Blue Nile and Redfox colleges. Students in these colleges come from mainly different districts of north Gondar. Due to complexity in terms of population size, diversity and origin of students, Gondar University was excluded from sampling frame.

\subsection{Source Population}

Source population consists of adolescents enrolled and actively learning in five public and private colleges, namely Gondar vocational college, Gondar regional College of teachers Education, Abyssinia health Science College, Gotoneal health Science College, Blue Nile college and Redfox animal health college.

\subsection{Study Design}

A Cross-sectional study design using pre-structured and pre-tested questionnaire survey was used to assess the existing patterns in alcohol consumption and associated factors among college students. It was focused on gender distribution, partner alcohol consumption behavior, family alcohol use history, type of alcoholic drink experienced and reason for preferences as well as collateral habits like khat chewing and cigarette smoking.

\subsection{Sample Size and Sampling}

For questionnaire survey on students, [19] derivation was followed to estimate for number of individuals to be included for the survey.

$$
n=\frac{Z_{\alpha}{ }^{2} P(1-P)}{e^{2}}
$$

Where $\mathrm{n}=$ Sample size required;

$\mathrm{Z}_{\alpha}=$ is the abscissa of normalized curve at confidence level $\alpha$

$\mathrm{e}=$ the desired level of precision;

$\mathrm{p}=$ the estimated proportion of an attribute.

Based on this, the following assumptions were made to calculate the number of individuals to be included in the survey. Since no published reports related to college student alcohol use in Gondar town, $50 \%$ prevalence was used to maximize the representativeness of sample. Non-response rate was expected to be $15 \%$. The $95 \%$ level of confidence and $5 \%$ desired level of precision were considered. Substituting for $Z_{\alpha}=1.96$ at $95 \% \quad C I ; \quad P=0.5 \quad(50 \%$ prevalence) $; \mathrm{e}=5 \%(0.05)$; Non response rate $=15 \%$, result in $\mathrm{n}=\left[1.96 * 1.96 *(0.5 * 0.5) /(0.05)^{2}\right] / 0.85=454$ individuals were included for questionnaire survey. For inclusion of participants, Gondar College of teacher education and Gotoneal health Science College were selected from two public and three private colleges using simple random sampling method. From college of teacher education seven classes on duty during day of survey were randomly selected. Objective and procedures for questionnaire briefed for students and 305-questionnaire format were distributed and recollected. Similarly, from Gotoneal health science college three classes on duty were randomly selected and 149 questionnaire formats were distributed and recollected.

\subsection{Data Collection and Processing}

All data obtained during each step of the data collection procedure was entered to Microsoft excel and exported into statistical software for social sciences (SPSS V. 20) for summarizing the data. Chi square $\left(\mathrm{X}^{2}\right)$ values were also used together with $\mathrm{P}$-value, odds ratio and confidence intervals. Descriptive statistical methods, such as tables with frequency and proportion were used to present prevalence of alcohol consumption experience by different factors considered. Pvalue $<0.05$ was considered statistically significant.

\subsection{Ethical Considerations}

Ethical clearance was obtained from Gondar University, 
College of Medicine and Health Sciences, Institutional Research Ethics Review Committee. The purpose and the importance of the study was explained and written consent was obtained from each participant. They were briefed about the confidentiality of their response and the importance of providing correct and accurate information, and voluntary participation. Permission was also obtained from both surveyed colleges.

\section{Results}

\section{Questionnaire Survey Findings}

Alcohol Use Prevalence

A total of 454 students participated in the study. All the study participants gave response to the distributed questioners. The total prevalence of alcohol use among college students at ever use and experience during last 30 days was found to be $48.23 \%$ and $26.4 \%$, respectively (Table 1 and Table 2). The prevalence of alcohol consumption experience under different participant categories namely gender, year of study, living style and religious background was summarized and a statistically significant difference in alcohol consumption prevalence existed between males $(67.6 \%, 34.1 \%)$ and females $(35.3 \%$, $21.32 \%)$; Muslims (12.8\%, $10.3 \%$ ) and Christians (51.6\%, $27.9 \%$ ) with both having P-values less than 0.05 at ever use and last 30 day basis (Table 1 and 2). No statistically significant difference in alcohol consumption proportion among groups categorized by their housing accommodation styles, $\mathrm{P}>0.05$ (Table 1).

\section{Reasons for alcohol consumption}

From reasons indicated by respondents, $39.7 \%$ of them depend on their previous experiences to select type of alcoholic beverage to consume, while only $7.3 \%$ of them rely on cost affordability (figure 2). Similarly, the motive behind alcohol drinking was also summarized and vast majority (48\%) has no reason as to why they consume alcohol, while $29.7 \%$ of them consume alcohol to get happiness and luxury (Figure 3). From analysis, respondents with alcohol consuming friend and family has greater likely hood for alcohol consumption behaviour compared to respondents having friends and families without experience of consumption of alcohol ( $\mathrm{P}<0.001, \mathrm{OR}>1)$ (Table 3$)$.

Alcohol consumption and related behaviors

The association of alcohol consumption and related behaviors were assessed from responses collected from questionnaire. Only $12(5.5 \%)$ of respondents with experience of alcohol consumption have experience of Khat chewing while 207 (94.5\%) of respondents with alcohol use experience have no history of Khat chewing. However, no statistically significance association was perceived and no significance in odds of Khat users with reference to their alcohol consumption status ( $\mathrm{P}>0.05)$ ( Table 4$)$.

Furthermore, association and risk of alcohol consumption and cigarette use was also assessed. Only 8 (3.7 \%) of respondents with alcohol consumption were found to experience cigarette smoking while the remaining of 211 (96.3\%) respondents having no experience of cigarette smoking. Similarly to Khat chewing, cigarette smoking was not associated with alcohol use experience $(\mathrm{P}>0.1)$ (Table 4).

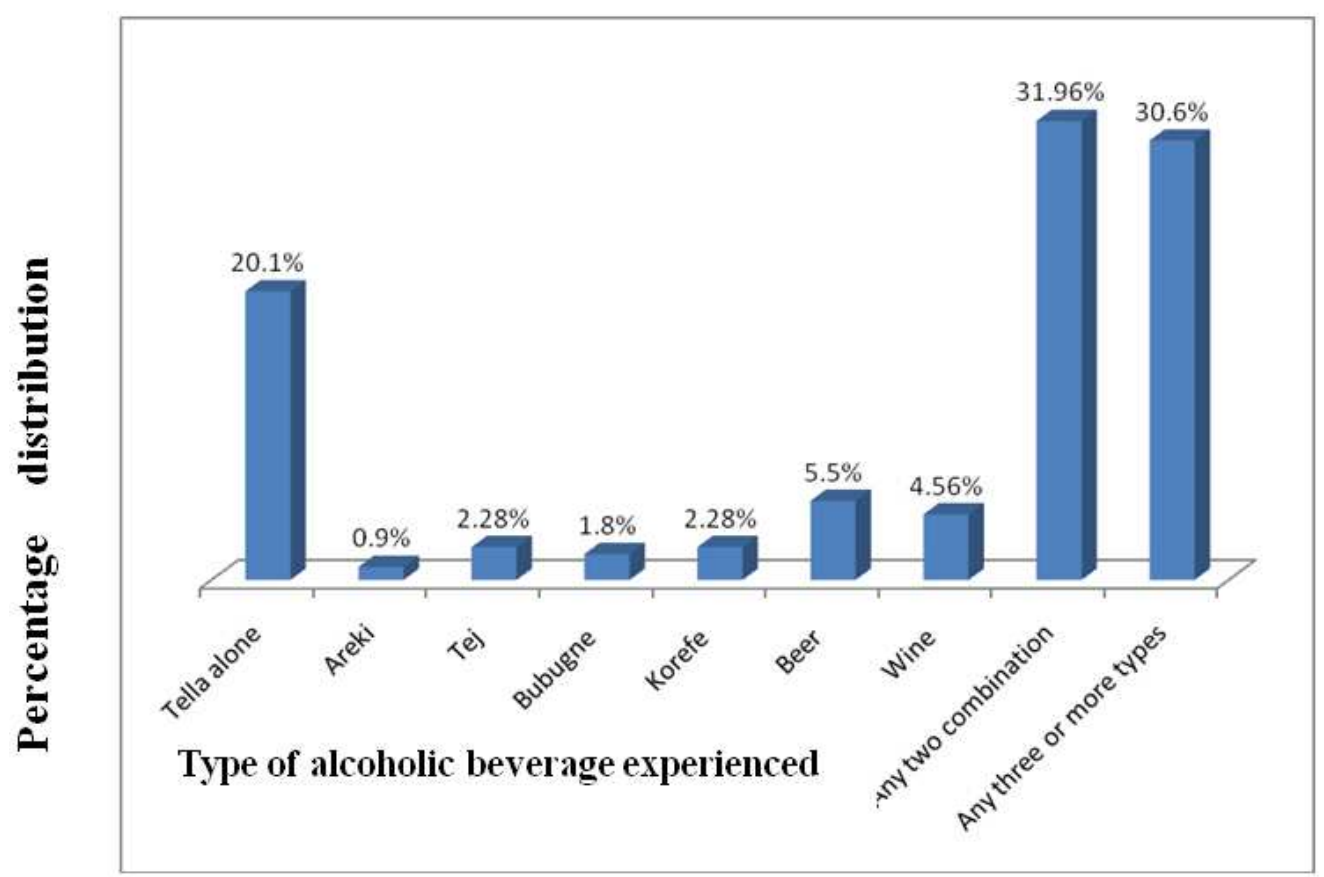

Figure 1. Percentage distribution of alcoholic beverages among those who consume alcohol $(n=219)$. 

Among College Students in Gondar Town, Northwest Ethiopia

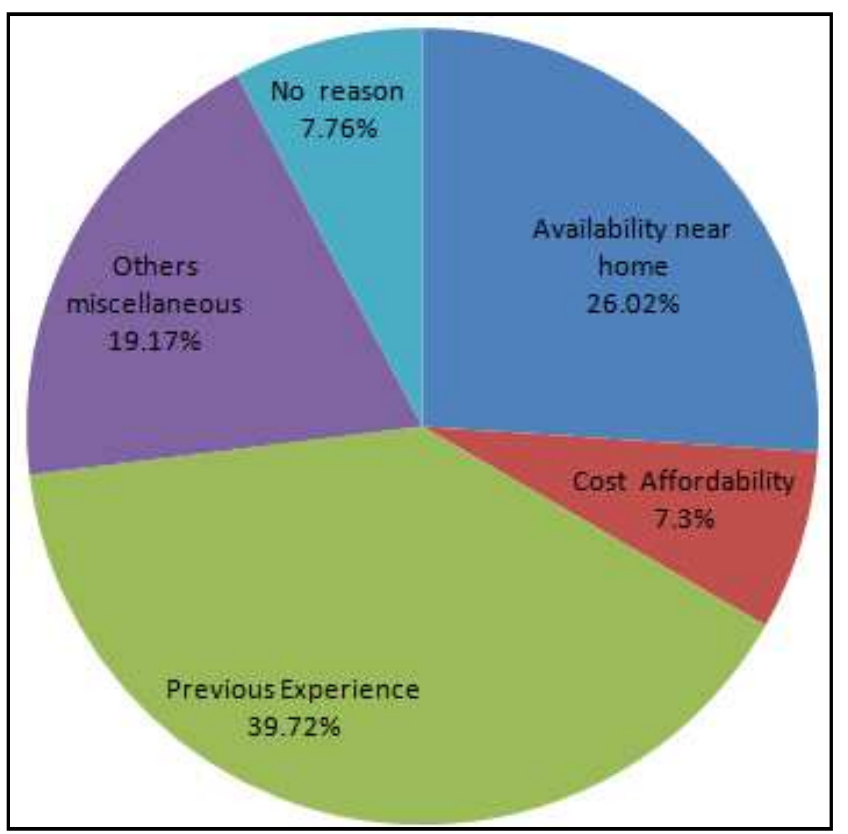

Figure 2. Percentage distribution of reasons for alcohol consumption preference ( $n=219)$.

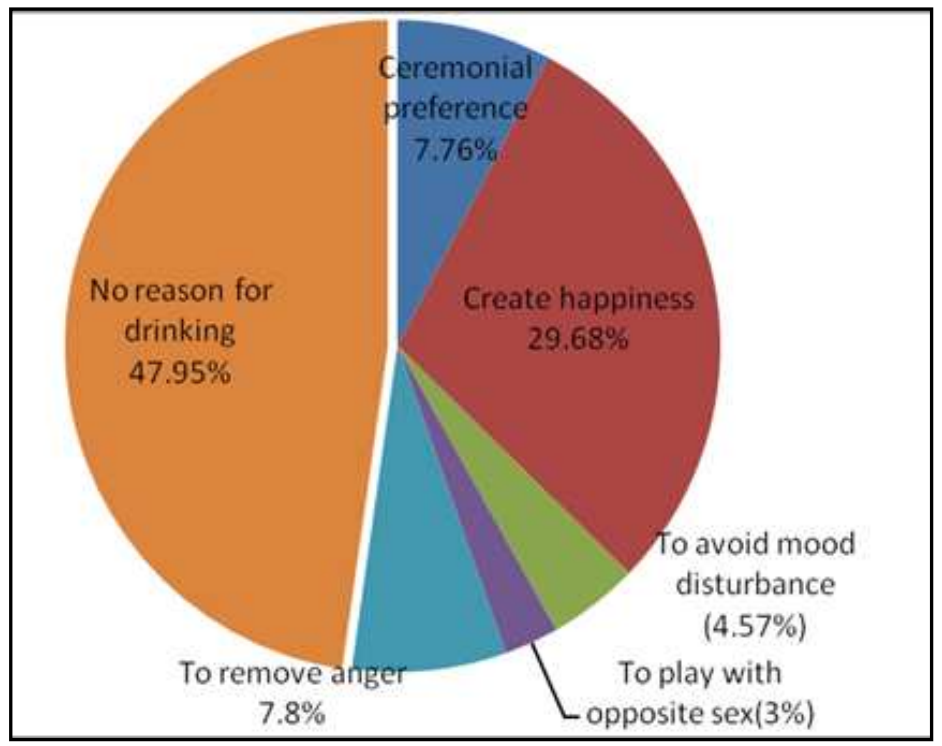

Figure 3. Percentage distribution reasons for alcohol consumption $(n=219)$.

Table 1. Prevalence of Alcohol use by categories of respondents as ever use basis $(n=454)$.

\begin{tabular}{|c|c|c|c|c|c|}
\hline \multirow{2}{*}{ Category } & & \multicolumn{3}{|c|}{ Alcohol consumption Experience } & \multirow{2}{*}{ Significance } \\
\hline & & Respondents & Number with alcohol experience & Proportion (\%) & \\
\hline \multirow{3}{*}{ Sex } & Female & 272 & 96 & 35.3 & \multirow{2}{*}{$\begin{array}{l}X^{2}=45.56 \\
P<0.001\end{array}$} \\
\hline & Male & 182 & 123 & 67.6 & \\
\hline & Freshman & 224 & 99 & 41.2 & \multirow{3}{*}{$\begin{array}{l}X^{2}=4.357 \\
P>0.05\end{array}$} \\
\hline \multirow[t]{2}{*}{ Year of study } & Sophomere & 172 & 92 & 53.5 & \\
\hline & Seniors & 58 & 27 & 46.6 & \\
\hline \multirow{2}{*}{ Religion } & Christians & 415 & 214 & 51.6 & \multirow{7}{*}{$\begin{array}{l}X^{2}=26.2 \\
P<0.001 \\
X^{2}=9.726 \\
P>0.05\end{array}$} \\
\hline & Muslims & 39 & 5 & 12.8 & \\
\hline \multirow[t]{4}{*}{ House accommodation Styles } & Parents & 200 & 87 & 43.5 & \\
\hline & Relative & 29 & 11 & 37.9 & \\
\hline & Friends & 118 & 67 & 56.7 & \\
\hline & Alone & 1.7 & 54 & 50.5 & \\
\hline Total & & 454 & 219 & 48.23 & \\
\hline
\end{tabular}


Table 2. Prevalence of alcohol use during the last thirty days of interview by respondents categories $(n=454)$.

\begin{tabular}{llllll}
\hline \multirow{2}{*}{ Category } & & \multicolumn{2}{l}{ Alcohol consumption Experience } & Significance \\
\cline { 3 - 5 } & & Respondents & Number with alcohol experience & Proportion (\%) & $\mathrm{X}^{2}=9.15$ \\
Sex & Female & 272 & 58 & 21.32 & $\mathrm{P}<0.005$ \\
& Male & 182 & 62 & 34.06 & \\
\multirow{3}{*}{ Year of study } & Freshman & 224 & 46 & 20.5 & $\mathrm{X}^{2}=8.77$ \\
& Sophomere & 172 & 53 & 30.8 & $\mathrm{P}<0.05(\mathrm{P}=0.03)$ \\
\multirow{2}{*}{ Religion } & Seniors & 58 & 21 & 36.2 & $\mathrm{X}^{2}=11.5$ \\
\multirow{2}{*}{ Total } & Christians & 415 & 116 & 27.95 & $\mathrm{P}<0.005$ \\
\hline
\end{tabular}

Table 3. Prevalence of alcohol consumption relative to friends' alcohol consumption $(n=454)$.

\begin{tabular}{lllll}
\hline $\begin{array}{l}\text { Personal Alcohol } \\
\text { consumption }\end{array}$ & Friends experience of Drinking & & Total & Significance \\
\cline { 2 - 4 } & With alcohol consuming friend & Without alcohol consuming friend & \\
\hline Pre sent & 144 & 75 & 219 & OR $=13.12[10.6,15.7]$ \\
Absent & 30 & 205 & 235 & $X^{2}=28.2 ; \mathrm{P}<0.001$ \\
Total & 105 & 349 & 454 & \\
\hline
\end{tabular}

Table 4. Prevalence of alcohol consumption and concomitant Khat and cigarette Consumption ( $n=454)$.

\begin{tabular}{|c|c|c|c|c|c|c|c|c|}
\hline \multirow{2}{*}{$\begin{array}{l}\text { Alcohol consumption } \\
\text { experience }\end{array}$} & \multicolumn{2}{|c|}{ Khat use experience } & \multirow{2}{*}{ Total } & \multirow{2}{*}{ Significance } & \multicolumn{2}{|c|}{$\begin{array}{l}\text { Cigarette smoking } \\
\text { experience }\end{array}$} & \multirow{2}{*}{ Total } & \multirow{2}{*}{ Significance } \\
\hline & With & Without & & & With & Without & & \\
\hline Alcohol Consumption & 12 & 207 & 219 & \multirow{3}{*}{$\begin{array}{l}\mathrm{OR}=1.18 ;[0.51,2.73] \\
\mathrm{X}^{2}=0.30 ; \mathrm{P}>0.1\end{array}$} & 8 & 211 & 219 & \multirow{3}{*}{$\begin{array}{l}\mathrm{OR}=2.932[0.77,11.2] \\
\mathrm{X}^{2}=2.71 ; \mathrm{P}>0.1\end{array}$} \\
\hline $\begin{array}{l}\text { No alcohol } \\
\text { Consumption }\end{array}$ & 11 & 224 & 235 & & 3 & 232 & 235 & \\
\hline Total & 23 & 431 & 454 & & 11 & 443 & 454 & \\
\hline
\end{tabular}

\section{Discussion}

From current study, alcohol consumption prevalence at ever use and last 30 day basis among college students of Gondar town was found to be $48.23 \%$ and $26.4 \%$ respectively. Similar result finding of lifetime prevalence rate of alcohol use, $51.9 \%$ was reported in college students from Eldoret, western Kenya [21]. Additionally in private Kenyan university with rates as high as $84 \%$ of alcohol use was also reported [16]. A study conducted in Debre Markos University shows greater prevalence rate of alcohol use at ever based (59\%) [22]. On the contrary, the global alcohol consumption report encountered was $29.8 \%$ for the entire population above 15 years of age [23]. A lower rate of alcohol use at ever use basis of $22.2 \%$ was reported in high school students from eastern Ethiopia [24]. This difference might have occurred due to cultural and regulation difference, the time the research was undertaken and variations in level of transparency.

Alcohol consumption experience under participant categories of gender has revealed significant difference in alcohol consumption between male $(67.6 \%, 34.1 \%)$ and females $(35.3 \%, 21.32 \%)$ at ever use and last 30 day experience basis, respectively. In line with the present study, many studies indicated that in both ever-use and use near to the survey periods, prevalence of alcohol use and exposure for alcohol drinking related problems are higher among males. Ethiopian national data record document, with female alcohol consumption at ever use basis was $17 \%$ which is less than males [23]. In Debre Markos University, three fold level of ever based alcohol use was reported in males than females[22]. Therefore, all research reports are in agreement with the level of alcohol use at ever use basis that females are more abstained.

Alcohol consumption prevalence by religious categories also show variations being Muslim participants with higher degree of both life time abstinence (87.2\%) and past time 30 day abstinence ( $89.3 \%$ ) unlike that of their Christian fellows life time abstinence $(48.4 \%)$ and alcohol use abstinence during last 30 day basis $(72.1 \%)$. In line with the present observation, the contribution of religion for societal level of alcohol use has been reported in many published articles. Lower proportion of Muslim high school students (27\%) relative to other faith categories of Orthodox (74\%) and Catholics (43\%) but greater than protestant groups $(20 \%)$ was reported [24]. The degree of commitment to religion (the same category) promoting abstinence from alcohol use was also reported [25]. Furthermore, differences in alcohol use or abstinence was reported among different categories with in Christian and Jewish religious categories [26]. The lower prevalence rate of alcohol drinking was reported in United States with greater number of Muslim population [27]. Religions of Islam and Buddhism prohibit followers of their religion from alcohol drinking while Christianity and Judaism have largely approached alcohol with mixed 
messages conceiving alcohol as both blessing and curse [28].

Alcohol consumption experience was not seen to show variation among respondents in different years of study and housing accommodation styles at both ever-use and for last 30 days experience basis. Similar findings on residency accommodation was encountered in studies from Kenyan private college student [21] and Haromaya university students [29]. Similarly, no association between year of study and substance use including alcohol, was reported in studies at Haromaya University. From questionnaire response analysis, Tella (20.1\%) was the most dominant local drink experienced by respondents. This might be attributable to its local preparation and cheaper cost compared to manufactured beverages. It was also known from cultural and historic value even before civilization. However, some of the respondents have experience of using both local and manufactured beverages.

From the current study findings, family and friends history of alcohol use experience, were associated with greater tendency for alcohol consumption. Behaviors of Cigarette use and Khat chewing were not statistically associated with alcohol consuming respondents. From studies in high school students in Ethiopia friend's history of alcohol was reported for risk of alcohol consumption [24].

Reasons of previous experiences and cost affordability were mentioned as prominent criteria for preference among alcoholic beverages which indicates possible target to manage alcohol use through taxation. From the current study findings, the motives behind alcohol drinking, like to get happiness and luxury, to entertain their partners and avoidance of distorted mood were indicated. Similar study reports were encountered on incentives to begin drinking such as reasons of meeting new people, making memories, enjoyment, escaping problems and get happy feeling in USA [30].

\section{Conclusions}

The proportion of students who have engaged in abusive alcohol use was significantly high. Therefore, we recommend that teaching learning environments should be regulated to minimize the risk of abusive alcohol use and related problems. Alcohol policies should be reviewed and prevention programmes should be initiated in light of research based evidence for this high-risk population group. Moreover, intervention activities to bring about behavioral change among the students are recommended.

\section{Authors' Contributions}

HK designed and compiled data collection materials, wrote the proposal and analyzed the data. SH was revised the proposal, collect the data, analyzed the data and finalized the write up of the manuscript. HK was responsible for critically revising the manuscript, and participated in its design and interpretation of the results from software analysis. Both authors reviewed and approved the final manuscript.

\section{Acknowledgements}

We are grateful to Mr. Mulugeta Fentie, head of school of pharmacy, Gondar University, for his kindness in writing letter of cooperation and facilitation of our research work. The kind cooperation by respondents, individuals in colleges and other offices were also appreciable.

\section{References}

[1] Reda A et al. (2012). Alcohol drinking patterns among high school students in Ethiopia: a cross-sectional study. BMC Public Health, 12:213.

[2] Rehm J et al. (2003): Alcohol as a risk factor for global burden of disease. Eur Addict. Res, 9:157-164.

[3] Rehm J et al. (2009). Alcohol, social development and infectious disease. Toronto, Centre for Addiction and Mental Health.

[4] Beaglehole, R. and Bonita, R.(2007): Alcohol: a global health priority. Lancet, 373:2173-2174.

[5] Awlan, A. ,(2011): Global status report on alcohol and health. In : World Health Organization WHO Library Cataloguing-inPublication Data, Geneva, Switzerland .ISBN 978924 1564151, pp 2-85

[6] Alem, A . and Kebede, D.(2006): Alcohol and substance abuse In Epidemiology and ecology of health and diseases in Ethiopia. (Edited by: Berhane Y, Haile- Mariam Damen, Kloos H.) Addis Ababa: Ethiopian Public Health Association (EPHA);:807-827.

[7] Shedler, J. and Block ,J.(1990): Adolescent drug use and psychological health. A longitudinal inquiry. Am. Psychol. 45:612-630.

[8] Merline, A, Jager, J, and Schulenberg, J.E.(2008): Adolescent risk factors for adult alcohol use and abuse: stability and change of predictive value across early and middle adulthood. Addiction, 103:84-99.

[9] Hingson. R, W, Heeren, T, Winter, M.R.(2006): Age at drinking onset and alcohol dependence: Age at onset, duration, and severity. Arch Pediatr Adolesc Med, 160:739-746.

[10] Grant, B., F., Stinson, F.,S. and Harford, T.,C.(2001): Age at onset of alcohol use and DSM- IV alcohol abuse and dependence: a 12-year follow-up. J Subst Abuse 13(4):493504 .

[11] Moore, E., Coffey, C., Carlin, J.B, Alati, R and Patton, G.,C. (2009): Assessing alcohol guidelines in teenagers: results from a 10-year prospective study. Aust N Z J Public Health, 33(2):154-159.

[12] Bonomo YA, Bowes G, Coffey C, Carlin JB, Patton GC(2004): Teenage drinking and the onset of alcohol dependence: a cohort study over seven years. Addiction, 99:1520-1528.

[13] Mason WA and Windle, M. (2001): Family, religious, school and peer influences on adolescent alcohol use: a longitudinal study. J Stud Alcohol, 62(1):44-53.

[14] Gruber E, DiClemente RJ, Anderson MM, Lodico M (1996): Early drinking onset and its association with alcohol use and 
problem behavior in late adolescence. Prev Med, 25:293-300.

[15] Kebede, D, Alem, A, Mitike ,G, Enquselassie,F, Berhane,F, Abebe ,Y, Ayele, R,Lemma,W, Assefa T, Gebremichael, T. (2005): Khat and alcohol use and risky sex behaviour among in school and out-of-school youth in Ethiopia. BMC Public Health, 5:109.

[16] Kuria, M., W. (1996): Drug abuse among urban as compared to rural secondary schools students in Kenya: a short communication. East Afr Med J, 73:339.

[17] Odek-Ogunde, M.and Pande-Leak D. (1999): Prevalence of substance use among students in a Kenyan University: a preliminary report. East Afr Med J, 76:301-306.

[18] Madu ,S., N., Matla ,M.,Q. (2003): Illicit drug use, cigarette smoking and alcohol drinking behaviour among a sample of high school adolescents in the Pietersburg area of the Northern Province, South Africa. J Adolesc, 26:121-136.

[19] Kasiulevičius, V., Šapoka, V. and Filipavičiūtè, R. (2006): Theory and practice Sample size calculation in epidemiological studies. Gerontologija; 7: 225-231.

[20] FDRECC (2005 updated); Measures against Alcoholism. Criminal code for federal democratic republic of Ethiopia. In URL:http://ethiopianlaws.wordpress.com/2011/09/21/criminal -code-of-the-federal-democratic-republic-of-ethiopia-may2005/ retrieved on 26/05/2014 3.00PM.

[21] Atwoli, L. Mungla, P., A. ,Ndung'u, M. N., Kinoti, K., C., and Ogot, E. M.( 2011): Prevalence of substance use among college students in Eldoret, western Kenya. BMC Psychiatry; 11: 34. PMCID: PMC3053226.

[22] Tesfahun Aklog, Gebeyaw Tiruneh and Girmay Tsegay (2013):Assessment of Substance Abuse and Associated Factors among Students of Debre Markos Poly Technique College in Debre Markos Town, East Gojjam Zone, Amhara Regional State, Ethiopia. Global Journal of Medical research. Pharma, Drug Discovery, Toxicology and Medicine,13 :5-15 ISSN: 2249-4618.

[23] WHO (2014): Management of Substance Abuse. Country Profiles, 2014. In URL: http://www.who. int/substance abuse/publications /global alcohol report/profiles/en/ 02/06/2014/8:30 AM.

accessed on

[24] Ayalu, A R., Asmamaw,M.,, Berhanu, Y., W.,, and Sibhatu B.(2012) : Alcohol drinking patterns among high school students in Ethiopia: a cross-sectional study. BMC Public Health , 12: 213. PMCID: PMC3328246.

[25] O’Malley, M., P., Johnston, D., L., and Bachman, G., J. (1998): Alcohol use among adolescents, 22:85-9. In URL: http://monitoringthefuture.org/pubs/text/pomldj98.pdf. accessed on 02/06/2014 AT 8:30 am.

[26] Ruth, C., E. and Mullen, K. (1999): The effect of religion and religiosity on drug use among a selected sample of post secondary students in Scotland. Addiction Research, 7:149170.

[27] Holt, J., B., Miller, W., J., Naimi, S.,T. and Sui ,D., Z. (2006):Religious Affiliation and Alcohol Consumption in the United States Geographical Review, 96: 523-542.In URL: http://www.jstor.org/stable/30034136 retrieved on 02/06/2014 AT 8:30 am.

[28] Robertson, C. K.(editor) (2004):Religion and Alcohol: Sobering Thoughts. New York Peter Lang. ISBN 978-0-82046793-1.In URL: http:/www.peterlang.com /download /datasheet /45854/datasheet 66793.pdf , retrieved on $02 / 06 / 2014$ at $8: 30 \mathrm{am}$.

[29] Andualem Derese, Assefa Seme, Chalachew Misganaw (2014) Assessment of substance use and risky sexual behavior among Haramaya University Students, Ethiopia. Science Journal of Public Health, 2: 102-110.

[30] Johnson E.,R. (2006):Expectancy, Mood, and Motive: An Exploration of Alcohol Consumption Motivations and Protective Drinking Strategies used by College Students. University of Minnesota Undergraduate Research Opportunities Program (UROP) College of Liberal Arts Undergraduate Research Grant University of Minnesota Duluth.http://epublications.bond.edu.au/cgi/viewcontent.cgi?a rticle $=1571 \&$ context $=$ hss $\_$pubs retrieved on $02 / 06 / 2014$ at 4:00pm. 